\title{
Chitosan based atorvastatin nanocrystals: effect of cationic charge on particle size, formulation stability, and in-vivo efficacy
}

This article was published in the following Dove Press journal:

International Journal of Nanomedicine

6 January 2015

Number of times this article has been viewed

\author{
Mallesh Kurakula' \\ AM El-Helw ${ }^{2}$ \\ Tariq R Sobahi' \\ Magdy Y Abdelaal' \\ 'Polymer Research Lab, Department \\ of Chemistry, Faculty of Science, King \\ Abdulaziz University, Jeddah, Saudi \\ Arabia; ${ }^{2}$ Department of Pharmaceutics, \\ Faculty of Pharmacy, King Abdulaziz \\ University, Jeddah, Saudi Arabia
}

\begin{abstract}
Cationic charged chitosan as stabilizer was evaluated in preparation of nanocrystals using probe sonication method. The influence of cationic charge densities of chitosan (low $\mathrm{CS}_{\mathrm{L}}$, medium $\mathrm{CS}_{\mathrm{M}}$, high $\mathrm{CS}_{\mathrm{H}}$ molecular weights) and $\mathrm{Labrasol}^{\circledR}$ in solubility enhancement and modifying the release was investigated, using atorvastatin (ATR) as poorly soluble model drug. Compared to $\mathrm{CS}_{\mathrm{M}}$ and $\mathrm{CS}_{\mathrm{H}}$; low cationic charge of $\mathrm{CS}_{\mathrm{L}}$ acted as both electrostatic and steric stabilizer by significant size reduction to $394 \mathrm{~nm}$ with charge of $21.5 \mathrm{meV}$. Solubility of ATR$\mathrm{CS}_{\mathrm{L}}$ increased to 60-fold relative to pure ATR and ATR-L. Nanocrystals were characterized for physiochemical properties. Scanning electron microscopy revealed scaffold-like structures with high surface area. X-ray powder diffractometry and differential scanning calorimetry revealed crystalline to slight amorphous state changes after cationic charge size reduction. Fourier transform-infrared spectra indicated no potent drug-excipient interactions. The enhanced dissolution profile of ATR-CS $\mathrm{L}_{\mathrm{L}}$ indicates that sustained release was achieved compared with ATR-L and Lipitor $^{\circledR}$. Anti-hyperlipidemic performance was $\mathrm{pH}$ dependent where ATR-CS $\mathrm{L}_{\mathrm{L}}$ exhibited 2.5fold higher efficacy at $\mathrm{pH} 5$ compared to $\mathrm{pH} 6$ and Lipitor $^{\circledR}$. Stability studies indicated marked changes in size and charge for ATR-L compared to ATR-CS ${ }_{L}$ exemplifying importance of the stabilizer. Therefore, nanocrystals developed with $\mathrm{CS}_{\mathrm{L}}$ as a stabilizer is a promising choice to enhance dissolution, stability, and in-vivo efficacy of major Biopharmaceutical Classification System II/IV drugs.
\end{abstract}

Keywords: atorvastatin, anti-hyperlipidemia, chitosan, cationic charge, stability, nanocrystals, in-vivo efficacy

\section{Introduction}

Among FDA approved drugs, 75\%-90\% entities turn up with poor or $\mathrm{pH}$ dependent solubility along with high gastro intestinal tract degradation and pre-systemic clearance, that owes to low bioavailability. ${ }^{1,2}$ (Biopharmaceutical Classification System class II/IV drugs). The major challenge to a formulation scientist is to develop a simple dosage form with improved drug solubility that can help in both enhancement of bioavailability and minimizing the adverse effects. The oldest technique, by physical modification of active pharmaceutical ingredient is a key strategy to improve the solubility, especially for those moieties which exhibit dissolution rate limited bioavailability. ${ }^{3}$ Nanosizing can be a non-specific approach to improve the bioavailability but is a proven principle paradigm to render an ideal pharmaceutical formulation. $^{4}$

Atorvastatin (ATR) ([R-( $\left.\left.\mathrm{R}^{*}, \mathrm{R}^{*}\right)\right]-2-(4-$ fluorophenyl)- $\beta, \delta$-dihydroxy-5(1-methylethyl)-3-phenyl-4-[(phenylamino)carbonyl]-1H-pyrrole-1-heptanoic acid, calcium salt (2:1) trihydrate), is a synthetic statin, acting as lipid lowering agent
Correspondence: Mallesh Kurakula Polymer Research Lab; Department of Chemistry, Faculty of Science, King Abdulaziz University, PO Box 80203 , Jeddah 21589, Saudi Arabia

Tel +9660540391082

Emailmallesh_kurakula@yahoo.com 
(Biopharmaceutical Classification System class II). ${ }^{5}$ ATR is a potent inhibitor of 3-hydroxy-3-methylglutaryl-co enzyme A reductase, preventing the conversion into mevalonate, which is a rate limiting step in hepatic cholesterol biosynthesis. ${ }^{6,7}$ ATR is reported to have $\mathrm{pH}$ dependent solubility. ${ }^{8}$ The drug undergoes high intestinal clearance and first-pass metabolism ${ }^{9}$ resulting in low absolute and systemic bioavailability which is about $14 \%$ and $30 \%$, respectively. ${ }^{10,11}$ Different formulation strategies for ATR have been reported to improve the solubility such as self-emulsifying drug delivery systems, ${ }^{12}$ self-micro emulsifying drug delivery systems, ${ }^{13}$ self-nano emulsifying drug delivery systems, ${ }^{14}$ conversion into amorphous nanoparticles using supercritical anti-solvent process, ${ }^{15}$ and micronization using anti-solvent precipitation process, ${ }^{16}$ but none of the formulation techniques were intended to modify or to enable sustain release of ATR along with limitations for their use.

Nanocrystals are nanosized (10-100 nm) pure form of drug in crystalline nature. Drug nanocrystals stand out from vesicular systems (liposomes) by several advantages like high loading capacity, stability, with scale up ease, and cost effectiveness. ${ }^{17}$ Nanosizing leads to increased surface area, exposing more surfaces which increases the saturation solubility and enhances the dissolution velocity according to Noyes-Whitney equation. ${ }^{18-20}$ Micronization or nanosizing can also lead to substantial increase in Gibbs free energy making the formulation unstable. The inherent property of agglomeration within formulation dispersion is a process of stabilization. A stabilizer that can overcome the agglomeration by providing sufficient steric or electro static repulsion between particles should be chosen and opted for. ${ }^{21}$ Until now, only few ionic surfactants (Cremophor ${ }^{\circledR}$ RH 40, Tween ${ }^{\circledR}$ 80 ) or non-ionic polymers (polyvinyl alcohol) individually or in combination have been examined in fabrication of nanocrystals or novel drug delivery systems. Earlier, the use of synthetic surfactants were reported with cytotoxicity effects due to high hydrophilic-lipophilic balance (HLB) value (HLB >14), poor biodegradability and immunogenicity. ${ }^{22}$ Identifying an ideal biodegradable stabilizer that can aid in the particle size reduction apart from stabilization of a nanocrystal formulation would be a breakthrough. ${ }^{23}$

Chitosan is a deacetylated product of chitin. The cationic charge polymer is biodegradable, biocompatible, nonimmunogenic, ${ }^{24}$ and non-toxic which aids its use in oral and intra-venous drug delivery systems. ${ }^{25}$ With a $\mathrm{pKa}$ of 6.5 , chitosan is slightly soluble in acidic medium but insoluble in neutral or alkaline medium. ${ }^{26}$ Depending upon the degree of de-polymerization, chitosan is available as low molecular weight chitosan $\left(\mathrm{CS}_{\mathrm{L}}\right)$, medium molecular weight chitosan $\left(\mathrm{CS}_{\mathrm{M}}\right)$, and high molecular weight chitosan $\left(\mathrm{CS}_{\mathrm{H}}\right)$ with different cationic charge densities and viscosities. ${ }^{27}$ The difference in cationic charge densities and stabilizer concentrations can have a significant effect on the fabrication of nanocrystals, stability, and its in-vivo performance. Recently, paclitaxe ${ }^{28}$ and docetaxel ${ }^{29}$ chitosan based conjugates have exhibited increased solubility, prolonged gastro intestinal tract retention, and ability to bypass first-pass metabolism with enhanced bioavailability.

Labrasol $^{\circledR}$ Gattefosse (Saint-Priest Cedex, France) is a non-ionic water dispersible surfactant (HLB 12) composed of well characterized polyethylene glycol esters, a small glyceride fraction and free polyethylene glycol esters. Labrasol's ${ }^{\circledR}$ surfactive power increases the wettability of ATR hydrophobic sites and helps to enhance the intrinsic solubility. ${ }^{30}$

Our research is aimed to improve the intrinsic solubility, dissolution release, and bioavailability of ATR by modifying the drug's physical state characteristics by using nanocrystal technique. Investigating an ideal concentration/molecular weight/cationic charge of chitosan for size reduction and stabilization of nanocrystals can be a promising strategy to formulate biodegradable sustained release formulation of ATR. The lyophilized chitosan based ATR nanocrystals were characterized for particle size, charge, crystalline nature, and drug-excipient interactions. Solubility, intrinsic dissolution

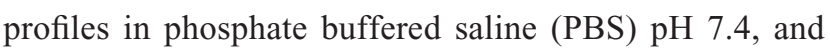
gastric stimulated fluid (GSF) pH 1.2 were examined. The in-vivo pharmacodynamic studies were also performed at determined $\mathrm{pH}$ to compare the therapeutic efficacy of ATR nanocrystals formulations over marketed product Lipitor ${ }^{\circledR}$ (Pfizer, Inc., New York, NY, USA) as control.

\section{Materials and methods Materials}

Atorvastatin (ATR) was a gift sample from Jamjoom Pharma, Saudi Arabia. Chitosan of different molecular weights $\left(\mathrm{CS}_{\mathrm{L}}-40, \mathrm{CS}_{\mathrm{M}}-480, \mathrm{CS}_{\mathrm{H}}-850 \mathrm{kDa}\right)$; viscosities $(20,200$, and $800 \mathrm{cps})$; degree of deacetylation $(92,82$, and 77) and poloxamer 407 were purchased from Sigma-Aldrich Co., St Louis, MO, USA. Labrasol ${ }^{\circledR}$ was received as gift from Gattefosse Co. (Saint Priest Cedex, France). Lipitor ${ }^{\circledR}$ (Pfizer. Inc., New York, NY, USA) 80 mg strip was a gift sample from King Abdulaziz Hospital, Saudi Arabia. Biochemical analysis kits to estimate total cholesterol, triglycerides, high density lipoprotein (HDL) and low density lipoprotein (LDL) levels were purchased from United Diagnostics Industry, 
Saudi Arabia. Organic solvents like acetonitrile, acetic acid, and methanol used were of analytical grade, purchased from Sigma-Aldrich Co. All other chemicals and solvents were of analytical grade. Deionized and distilled water was used throughout the study.

\section{Preparation of ATR nanocrystals}

Nanocrystals were prepared by combination of antisolvent precipitation process followed by probe sonication method. ${ }^{31}$ Briefly, organic feeds were prepared by dissolving $80 \mathrm{mg}$ of ATR and Labrasol ${ }^{\circledR}(0.5 \% \mathrm{w} / \mathrm{w})$ in methanol. Then the organic feeds were injected instantaneously into polymer solution containing chitosan and were prehomogenized at 12,000 rpm for 2 minutes (Ultra-turrax T-25 1KA, Germany). The dispersion was further processed for particle size reduction using probe sonication (Sonics Vibra cell, VCX 750; Sonics \& Materials, Inc., Newtown, CT, USA) at $20-23 \mathrm{kHz}$ for 4 minutes to prepare $1 \% \mathrm{w} / \mathrm{w}$ ATR nanocrystals. The process was established and repeated to fabricate ATR nanocrystals using Labrasol ${ }^{\circledR}$ alone and in combination with three different molecular weight chitosan $\left(\mathrm{CS}_{\mathrm{L}}, \mathrm{CS}_{\mathrm{M}}, \mathrm{CS}_{\mathrm{H}}\right)$. Further, the final colloidal dispersions of all batches were lyophilized (Christ alpha 1-2-LD plus, Germany) to obtain powder chitosan based ATR nanocrystals.

\section{Aqueous solubility of ATR nanocrystals}

Enhancement of saturation solubility of ATR after nanosizing was determined by shake flask method using orbital shaking incubator (GFL 1083; GFL, Burgwedel, Germany). Excess of pure ATR and different nanocrystal batches, ATR-L (ATR nanocrystals stabilized by Labrasol ${ }^{\circledR}$ alone), ATR-CS ${ }_{L}, \mathrm{CS}_{\mathrm{M}}$ and $\mathrm{CS}_{\mathrm{H}}$ were added to deionized water $(10 \mathrm{~mL})$. The solutions were transferred into individual flasks, sealed and shaken at $37^{\circ} \mathrm{C} \pm 0.5^{\circ} \mathrm{C}$ for 72 hours. ${ }^{32}$ After the attainment of equilibrium, $5 \mathrm{~mL}$ of aliquots were withdrawn, centrifuged 15,000 rpm for 15 minutes (Sigma-Aldrich Co.) and filtered using $0.10 \mu \mathrm{m}$ membrane filter before high performance liquid chromatography (HPLC) analysis. All the samples were analyzed in triplicate $(n=3)$.

\section{Characterization of ATR nanocrystals} Particle size analysis

The particle size and polydispersity index were determined by photon correlation spectroscopy using Zetasizer NanoZS (Zetatrac NPA $152-31 \mathrm{~A}, \mathrm{USA}$ ) at $25^{\circ} \mathrm{C}$. The lyophilized ATR nanocrystals were redispersed with $5 \mathrm{~mL}$ distilled water in order to obtain accurate scattering intensity before the measurement. All the samples were analyzed in triplicate $(n=3)$.

\section{Zeta potential analysis}

The particle charge was measured by determining the particle electrophoretic mobility using Zetasizer NanoZS (Zetatrac NPA $152-31 \mathrm{~A}$ ) at $25^{\circ} \mathrm{C}$. The values were calculated using Helmholtz-Smoluchowski equation. The lyophilized ATR nanocrystals were diluted 80 times with filtered deionized water to obtain ideal concentration range for optimal measurement. ${ }^{23}$ (Viscosity values of the dispersion media were made less than equivalent to water [1.0 $\mathrm{mPas}]$ at $25^{\circ} \mathrm{C}$ ).

\section{Particle morphology}

The Surface morphology was characterized by using scanning electron microscope (SEM) (Carl Zeiss Meditec AG, Jena, Germany). The lyophilized nanocrystals were carefully fixed onto the double sided tape of aluminum stub and coated with gold for 5 minutes under vacuum. The morphology of nanocrystals was examined and recorded.

\section{Crystalline studies}

The change in the thermal properties of pure ATR, chitosan, ATR-L, and ATR-CS $\mathrm{L}_{\mathrm{L}}$ nanocrystal formulations before and after size reduction were recorded using DSC 131 EVO, SETARAM Instrumentation, Caluire, France. Three milligrams of each sample was placed onto the aluminum crucible and sealed. The thermograms were recorded at a scanning rate from $35^{\circ} \mathrm{C}$ to $300^{\circ} \mathrm{C}$ with an increase of $10^{\circ} \mathrm{C} / \mathrm{min}$. $\mathrm{X}$-ray powder diffractometry conformational changes in the crystalline state of ATR, excipients, and lyophilized ATR nanocrystals were investigated by using D8 Advance, Bruker AXS Inc., Madison, WI, USA. The instrument was operated at scanning rate of $1 \% \mathrm{~min}$ for $2 \theta$ of $70^{\circ}$.

\section{Drug-excipient interaction studies}

In order to investigate the extent of drug-excipient compatibility, Fourier transform-infrared (FT-IR) spectra of pure ATR, chitosan, ATR-L, and ATR-CS nanocrystals were recorded within the spectral region of 4,000 and $400 \mathrm{~cm}^{-1}$ (Alpha T, Bruker AXS Inc.). Infra red (IR) pellets were made by compressing the mixture of IR grade potassium bromide along with sample in the ratio of $1: 100$.

\section{In-vitro dissolution studies}

Dissolution studies were evaluated according to USP Apparatus II method using ERWEKA DT 700 LH, Germany. 
Pure ATR, ATR-L, and ATR-CS $\mathrm{L}_{\mathrm{L}}$ nanocrystals, equivalent to $80 \mathrm{mg}$ of ATR, were filled into $00 \#$ gelatin capsules. The capsules filled with nanocrystal formulations were placed inside the dissolution flask, with $900 \mathrm{~mL}$ of PBS (pH 7.4) and GSF (pH 1.2) with constant stirring rate of $50 \mathrm{rpm}$ at $37^{\circ} \mathrm{C}$. Five milliliters of samples were withdrawn at $0.5,1,2,4,6$, 8,10 , and 12 hours respectively and immediately replaced with respective dissolution media in order to maintain sink conditions. ${ }^{32}$ The samples were filtered through $0.10 \mu \mathrm{m}$ filter membranes before HPLC analysis. The dissolution profiles were drawn and summarized in comparison with marketed product ie, $80 \mathrm{mg}$ Lipitor ${ }^{\circledR}$ as standard. All the samples were analyzed in triplicate $(n=3)$.

\section{In-vivo anti-hyperlipidemic efficacy studies}

The animal studies were approved and performed in accordance with guidelines of Animal Research Ethical Committee of King Abdulaziz University, Faculty of Medicine, Saudi Arabia. Male Wistar rats (220-300 g) were divided into six groups having six animals each.

- Group I - untreated as negative control.

- Group II - poloxamer 407 induced hyperlipidemic as positive control.

- Group III - poloxamer 407 induced hyperlipidemic treated with ATR-L formulation.

- Group IV - poloxamer 407 induced hyperlipidemic

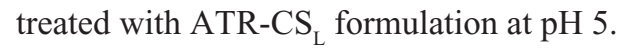

- Group V-poloxamer 407 induced hyperlipidemic treated

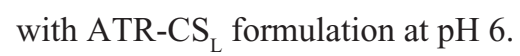

- Group VI - poloxamer 407 induced hyperlipidemic treated with Lipitor ${ }^{\circledR}$ as standard.

In order to induce hyperlipidemia, the animals were injected intraperitoneally with $0.25 \mathrm{~g} / \mathrm{kg}$ poloxamer 407 , (Sigma-Aldrich Co.) which was dissolved in $0.9 \%$ saline. ${ }^{33}$ Eighteen gauge feeding needle was used for oral dosing of ATR nanocrystal formulations to the animals. Blood samples were withdrawn from retro-orbital sinus plexus at intervals of $0,24,48$, and 72 hours. The blood samples were collected and preserved in vacutainer tubes. The serum was separated by centrifugation at 10,000 rpm for 5 minutes (Sigma 3 K30, Germany). Further biochemical analysis for extent of inhibition and estimation of total serum cholesterol, triglycerides, LDL, and HDL was done using diagnostic kits (United Diagnostics, Saudi Arabia). Statistical analysis of the collected data was performed using one way analysis of variance (ANOVA).

\section{HPLC analysis of ATR}

Newer reverse phase HPLC method was developed and validated according to International Conference of Harmonisation guidelines Q2 (R1) ${ }^{34}$ in order to quantify, as well as determine the saturation solubility and dissolution rates of the ATR nanocrystal formulations. ${ }^{35}$ The HPLC auto sampler system (Agilent Series 1200; Agilent Technologies, Santa Clara, CA, USA) was equipped with 1260 Infinity Diode Array $(80 \mathrm{~Hz})$ detector and Eclipse $\mathrm{XDB}^{\circledR}$ $5 \mu \mathrm{m}(4.6 \times 150 \mathrm{~mm})$ column. A mobile phase as a combination of acetonitrile-buffer $(0.025 \mathrm{M}$ potassium dihydrogen orthophosphate of $\mathrm{pH} 5)(45: 55 \mathrm{v} / \mathrm{v})$ with a flow rate of $1.5 \mathrm{~mL} / \mathrm{min}$ was used. The injection volume was $5 \mu \mathrm{L}$ and the ATR concentration was determined at $247 \mathrm{~nm}$.

\section{Stability studies}

In order to assess the role of cationic charge over physical stability of ATR nanocrystals, short-term stability studies were performed according to International Conference of Harmonisation guidelines. ${ }^{36}$ The optimized nanocrystal formulations, ATR-L and ATR-CS $\mathrm{L}_{\mathrm{L}}$ in dry powder form were filled in each glass vial and sealed. Individual vials were stored at elevated temperatures like 4,25 , and $40^{\circ} \mathrm{C}$ for 90 days in stability chamber (CHM 10S; REMI Laboratory Instruments, Mumbai, India). The samples were analyzed at 0 and 90 days. The formulations were examined for physical stability in terms of change in particle size and zeta potential.

\section{Statistical analysis}

All results are depicted as the mean value \pm standard deviation. Significance of difference was evaluated using one way ANOVA at probability level of 0.05 .

\section{Results and discussion}

The fabrication process was optimized to obtain uniform particle size ATR nanocrystals. A combinatorial approach as anti-solvent precipitation followed by probe sonication method was evaluated and optimized. The drop wise addition of drug solution into stabilizer dispersion had efficiently precipitated the ATR as crystals due to the interference with intrinsic solubility of the drug. The colloidal solution was probe sonicated for particle size reduction ie, top-down approach $^{19}$ and further lyophilized. Optimization of probe sonication time was a critical factor in the size reduction process and nanocrystals' fabrication. In early stages, particles in 1,054 $\pm 74 \mathrm{~nm}$ range were obtained for 3 minutes, while 
increase in sonication time to 6 minutes showed increase in particle size reduction of about $364 \pm 15 \mathrm{~nm}$. However, further increase up to 9 minutes could not reduce particle size but resulted in agglomeration process. Therefore, 6 minutes of probe sonication was sufficient to get uniform particle size and was considered optimum throughout the experimental design.

\section{Effect of surfactant}

Surfactant:polymer ratio plays a vital role in the preparation of nanocrystal formulation. Surfactant helps in enhancing the solubility, by providing sufficient wetting of ATR hydrophobic surfaces. A surfactant with HLB $\leq 14$ is safer for human use. ${ }^{22}$ Few non-ionic polymers and surfactants such as poly vinyl alcohol and Tween 40, 80 were also examined initially but resulted in larger particle size and agglomeration. For this purpose and concern, Labrasol ${ }^{\circledR}$ as newer non-ionic water surfactant (HLB 12) was investigated in the present work. Preliminary studies were carried out on the stabilizing potential of Labrasol ${ }^{\circledR}$ in the nanocrystal formulation and $0.5 \% \mathrm{w} / \mathrm{w}$ was selected as optimized concentration throughout the work. Moreover $0.5 \% \mathrm{w} / \mathrm{w}$ concentration was earlier assessed for cytotoxicity and proved to be safe for human use. ${ }^{22}$ Interestingly, $0.5 \% \mathrm{w} / \mathrm{w}$ concentration exhibited profound effects by increasing the solubility of ATR but the particle size obtained with Labrasol ${ }^{\circledR}$ alone was relatively very large $\sim 600 \mathrm{~nm}$. Also the nanocrystals exhibited slight negative charge with sedimentation after 4 days of preparation due to the Brownian movement; this phenomenon proved that wettability of hydrophobic surfaces of ATR alone is not sufficient to prevent sedimentation or particle size reduction. This also implicated the need and importance of suitable stabilizer within formulation that can inhibit the Ostwald aggregation. Cationic charge polymers are expected to be adsorbed on the surface of particles providing electrostatic or steric repulsions preventing the aggregation. Therefore, chitosan in different molecular weights having varied cationic charge densities were investigated for its role in nanocrystal stabilization in combination with Labrasol ${ }^{\circledR}$.

\section{Effect of chitosan concentration}

In the preliminary studies, $\mathrm{CS}_{\mathrm{L}}$ was considered as stabilizer due to its lower cationic charge, in order to study the significant impact of polymer over particle size reduction and stability. Different concentrations of $\mathrm{CS}_{\mathrm{L}}$ with substantial increase of $0.05 \%(\mathrm{w} / \mathrm{w})$ were evaluated in order to optimize nanocrystals. The produced nanocrystals were measured for

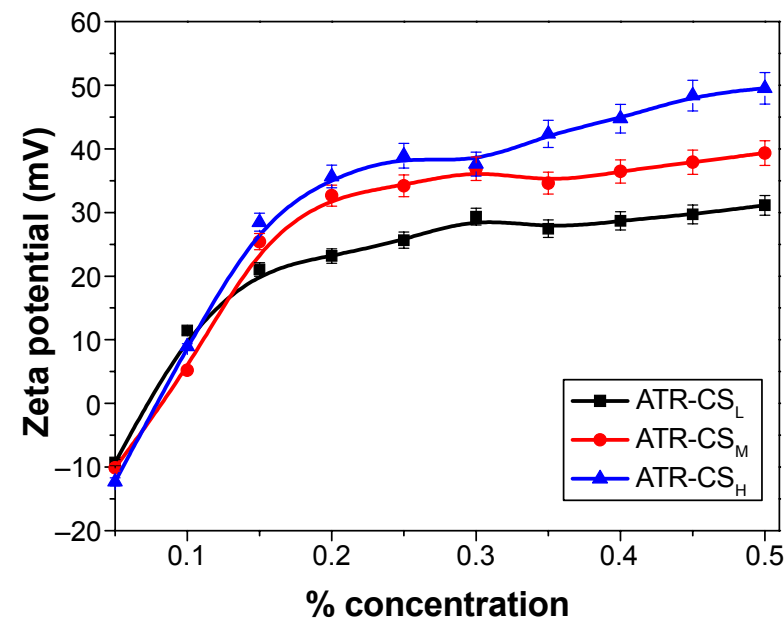

Figure I Zeta potential values of atorvastatin nanocrystal formulations stabilized by $0.5 \%$ Labrasol $^{\circledast}(\mathrm{w} / \mathrm{w})$, with $\mathrm{CS}_{\mathrm{L}}, \mathrm{CS}_{\mathrm{M}}$, and $\mathrm{CS}_{\mathrm{H}}$ of different concentrations at $\mathrm{pH} 5$. Note: Labrasol ${ }^{\circledR}$ (Gattefosse, Saint-Priest Cedex, France).

Abbreviations: ATR, atorvastatin; $C S$, chitosan; $\mathrm{CS}_{L}$, low molecular weight chitosan; $\mathrm{CS}_{\mathrm{M}}$, medium molecular weight chitosan; $\mathrm{CS}_{\mathrm{H}}$, high molecular weight chitosan.

mean particle size and zeta potential respectively (Figure 1). As the concentration of $\mathrm{CS}_{\mathrm{L}}$ was increased, the zeta potential also increased and leveled off at $0.3 \% \mathrm{w} / \mathrm{w}$ indicating equilibrium point of polymer adsorption. The reduction in size and zeta potential were found to be increased with marginal increase of $\mathrm{CS}_{\mathrm{L}}$ concentration $(0.05 \%[\mathrm{w} / \mathrm{w}])$ majorly due to electrostatic stabilization. But further increase of $\mathrm{CS}_{\mathrm{L}}$ concentration to 0.4 and $0.5 \%(\mathrm{w} / \mathrm{w})$ resulted in higher particle size and agglomeration. Based on these studies, chitosan of $0.3 \%$ $(w / w)$ concentration was established as optimum for preparation of ATR nanocrystal formulations throughout the study.

\section{Effect of chitosan molecular weight}

Cationic charge density is directly proportional to the molecular weight of the respective chitosan. Indeed they exhibit different adsorption properties over the drug surfaces. In order to determine the effect of different molecular weight on size reduction, agglomeration and stability $0.3 \%(\mathrm{w} / \mathrm{w})$ was kept as optimum concentration for fabrication of ATR-CS ${ }_{L}$, $\mathrm{CS}_{\mathrm{M}}$, and $\mathrm{CS}_{\mathrm{H}}$ nanocrystals The particle size of ATR-L was found significantly greater than ATR nanocrystals stabilized by $\mathrm{CS}_{\mathrm{L}}, \mathrm{CS}_{\mathrm{M}}$, and $\mathrm{CS}_{\mathrm{H}}$ majorly due to the absence of cationic polymer steric protection effect. It was clearly evident that zeta potential was increased up from 21 to $32.19 \mathrm{meV}$ among ATR-CS ${ }_{\mathrm{L}}$ to $\mathrm{CS}_{\mathrm{H}}$ indicating that steric protection effect was subsequently increased with marginal increase in molecular weights of chitosan. Therefore, variation in the average mean of particle size was observed and found to be increased from $\mathrm{CS}_{\mathrm{L}}$ to $\mathrm{CS}_{\mathrm{H}}$ ie, 340 to $440 \mathrm{~nm}$. Moreover, the sizes of particles 
Table I Properties of atorvastatin nanocrystals stabilized by Labrasol ${ }^{\circledR} 0.5 \%(\mathrm{w} / \mathrm{w})$ alone and along with $0.3 \%$ (w/w) cationic polymers $\left(\mathrm{CS}_{\mathrm{L}}, \mathrm{CS}_{\mathrm{M}}\right.$, and $\left.\mathrm{CS}_{\mathrm{H}}\right)(\mathrm{n}=3)$

\begin{tabular}{llll}
\hline Formulations & Particle size $(\mathbf{n m})$ & Polydispersity index & Zeta potential $(\mathbf{m V})$ \\
\hline ATR-L & $551.6 \pm 21.5$ & $0.321 \pm 0.031$ & $-14.26 \pm 1.5$ \\
ATR-CS & $349.9 \pm 41.3$ & $0.312 \pm 0.016$ & $21.57 \pm 2.1$ \\
ATR-CS & $392.5 \pm 27.6$ & $0.298 \pm 0.018$ & $27.21 \pm 2.6$ \\
ATR-CS & $439.5 \pm 23.9$ & $0.267 \pm 0.021$ & $32.19 \pm 2.9$ \\
\hline
\end{tabular}

Note: Labrasol ${ }^{\oplus}$; Gattefosse, Saint-Priest Cedex, France.

Abbreviations: ATR, atorvastatin; CS, chitosan; $\mathrm{CS}_{\mathrm{L}}$, low molecular weight chitosan; $\mathrm{CS}_{\mathrm{M}}$, medium molecular weight chitosan; $\mathrm{CS}_{\mathrm{H}}$, high molecular weight chitosan; ATR-L, atorvastatin nanocrystals stabilized by Labrasol ${ }^{\circledR}$ alone.

of nanocrystals stabilized with $\mathrm{CS}_{\mathrm{L}}$ were much smaller when compared to $\mathrm{CS}_{\mathrm{M}}$ and $\mathrm{CS}_{\mathrm{H}}($ Table 1).

\section{Effect of polymer charge density}

Different molecular weights of chitosan $\left(\mathrm{CS}_{\mathrm{L}}, \mathrm{CS}_{\mathrm{M}}\right.$, and $\left.\mathrm{CS}_{\mathrm{H}}\right)$ were selected to investigate the effect of the cationic charge density on particle size reduction. Despite the difference in charge densities, similar trend of particle size and zeta potential values was observed and even the equilibrium adsorption concentration of $\mathrm{CS}_{\mathrm{M}}$ and $\mathrm{CS}_{\mathrm{H}}$ were almost the same as that of $\mathrm{CS}_{\mathrm{L}}$ (Figure 2). But there was a noticeable increase in the surface charge of ATR-CS ${ }_{\mathrm{H}}$ nanocrystals and the extent of size reduction was different and lower compared to $\mathrm{CS}_{\mathrm{L}} / \mathrm{CS}_{\mathrm{M}}$ (Table 1). The zeta potential values of nanocrystals were in the order of $\mathrm{CS}_{\mathrm{H}}>\mathrm{CS}_{\mathrm{M}}>\mathrm{CS}_{\mathrm{L}}$. Among others, cationic charge density of $\mathrm{CS}_{\mathrm{L}}$ has excelled in significant size reduction by providing sufficient surface charge and better electrostatic stabilization. Therefore, ATR nanocrystals stabilized by $0.3 \%(\mathrm{w} / \mathrm{w}) \mathrm{CS}_{\mathrm{L}}$ were selected for further characterizations and evaluations in the study.

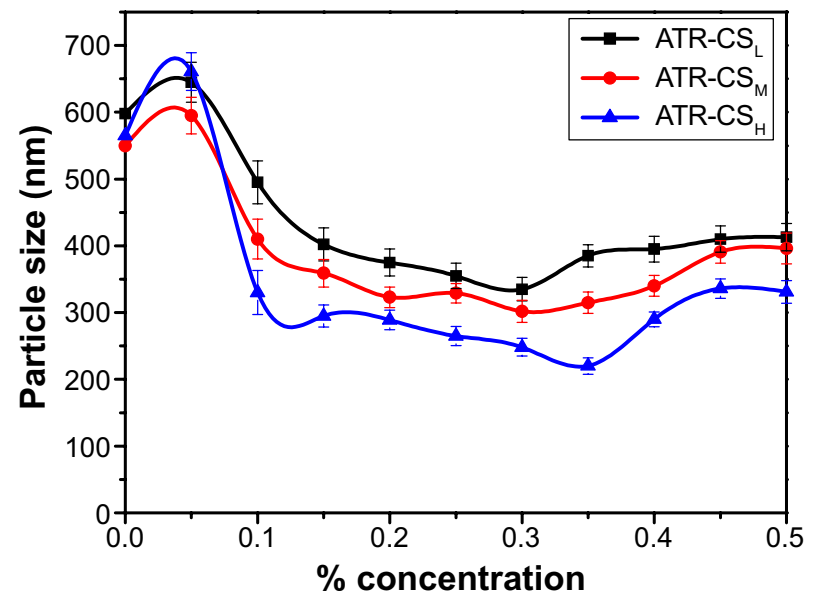

Figure 2 Particle size values of atorvastatin nanocrystal formulations stabilized by $0.5 \%$ Labrasol $^{\circledR}(\mathrm{w} / \mathrm{w})$ with $\mathrm{CS}_{\mathrm{L}}, \mathrm{CS}_{\mathrm{M}}$, and $\mathrm{CS}_{\mathrm{H}}$ of different concentrations at $\mathrm{pH} 5$. Note: Labrasol ${ }^{\circledast}$ (Gattefosse, Saint-Priest Cedex, France).

Abbreviations: ATR, atorvastatin; $\mathrm{CS}$, chitosan; $\mathrm{CS}_{\mathrm{L}}$, low molecular weight chitosan; $\mathrm{CS}_{\mathrm{M}}$, medium molecular weight chitosan; $\mathrm{CS}_{\mathrm{H}}$, high molecular weight chitosan.

\section{Solubility studies}

The aqueous solubility of pure ATR, ATR-L, ATR-CS , ATR-CS ${ }_{\mathrm{M}}$, and ATR-CS $\mathrm{H}_{\mathrm{H}}$ nanocrystals was found to be 24.5; $495.6 ; 1,456.1 ; 1,143.2$; and $1,079.6 \mu \mathrm{g} / \mathrm{mL}$ respectively. As the particle size was reduced, the surface area of the particles was increased, thereby enhancing the drug saturation solubility. ${ }^{20}$ ATR-CS ${ }_{\mathrm{L}}$ nanocrystal formulation solubility was increased approximately 60 -fold when compared to pure ATR and ATR-L. The improved solubility of ATR was a collective effect attributed to the presence of Labrasol ${ }^{\circledR}$ as surfactant and cationic charge polymer size reduction.

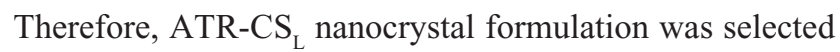
for further studies, since it showed significantly higher solubility profile when compared to ATR-L, ATR-CS ${ }_{\mathrm{M}}$, and ATR-CS ${ }_{H}$ formulations. The enhancement of ATR solubility will greatly affect the in-vitro dissolution behavior of the ATR nanocrystal formulation.

\section{Morphology studies}

The surface morphology before and after the cationic charge nanonization of ATR was examined using scanning electron microscopy. The scanning electron microscopy images of nanocrystal formulations revealed rough scaffold-like structures with high surface area. The particle size was greatly reduced with smooth surfaces by probe sonication when compared to unmodified ATR or pure drug. The crystals of ATR$\mathrm{CS}_{\mathrm{L}}$ formulation were different from others and the particles were greatly reduced in size with high surface area indicating multiple scaffold-like structures (Figure 3). This could be the major reason for enhanced aqueous solubility of ATR-CS when compared to other nanocrystal formulations.

\section{Crystalline studies}

The existence of ATR in crystalline state is a principle indicator, which determines the extent of nanocrystal solubility. Differential scanning calorimetry (DSC) thermograms were recorded both before and after the cationic polymer nanosizing. The DSC revealed characteristic peaks of pure ATR $\left(162.8^{\circ} \mathrm{C}\right)$, chitosan 
A

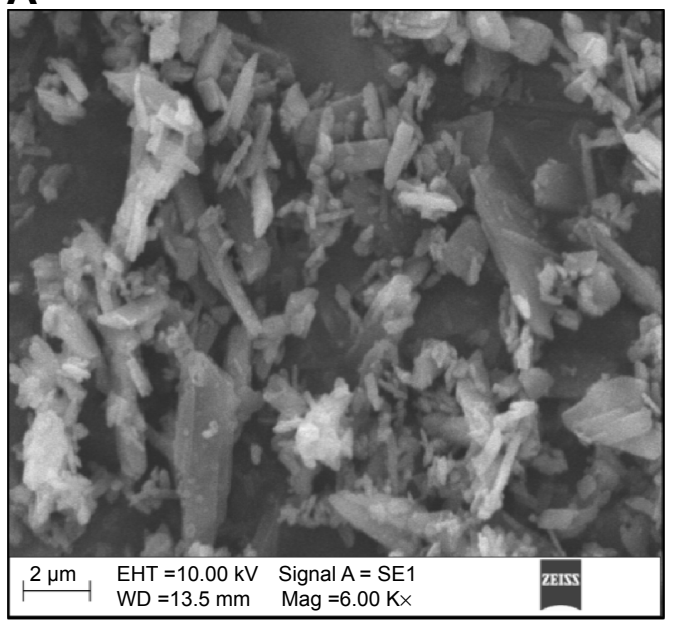

C

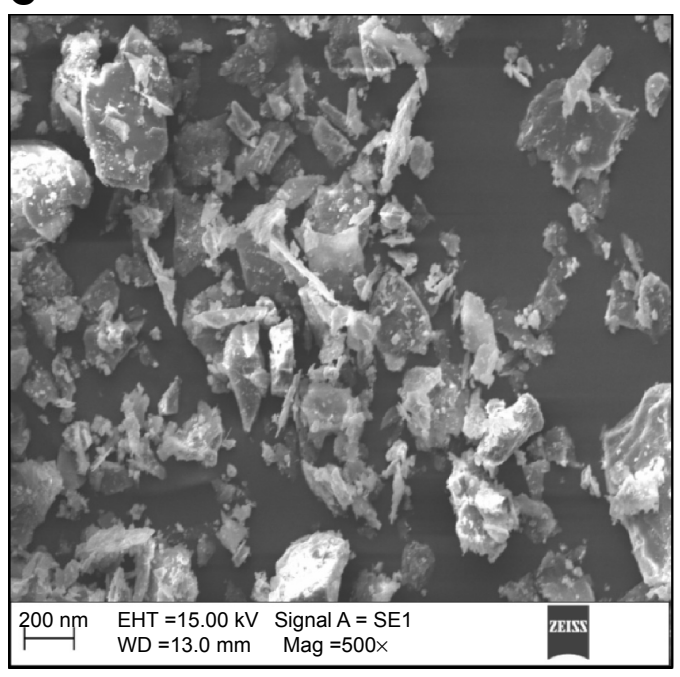

E

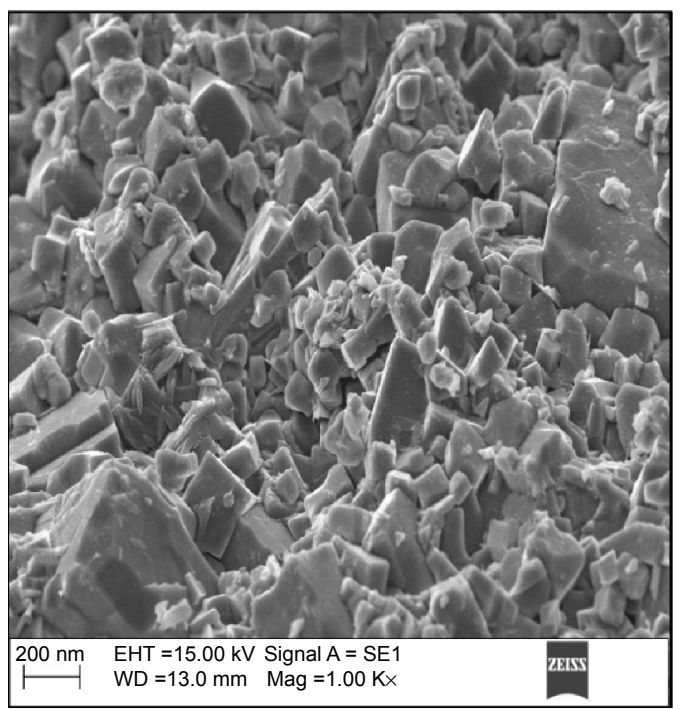

B

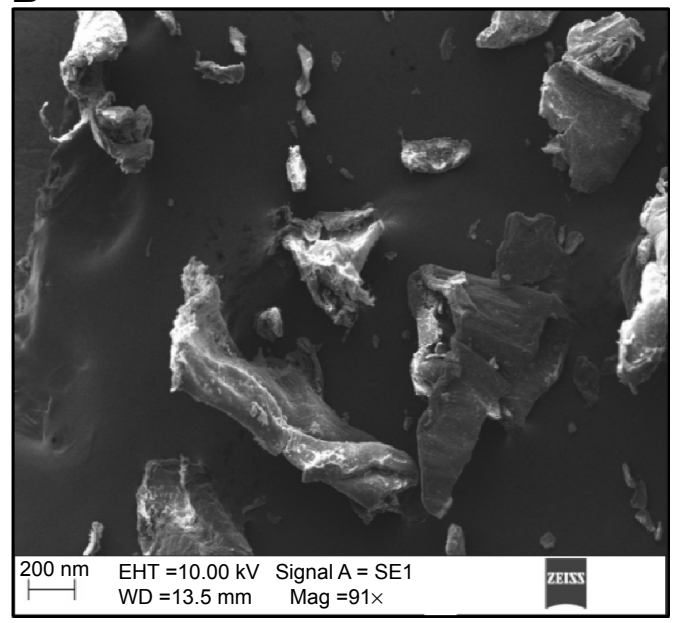

D

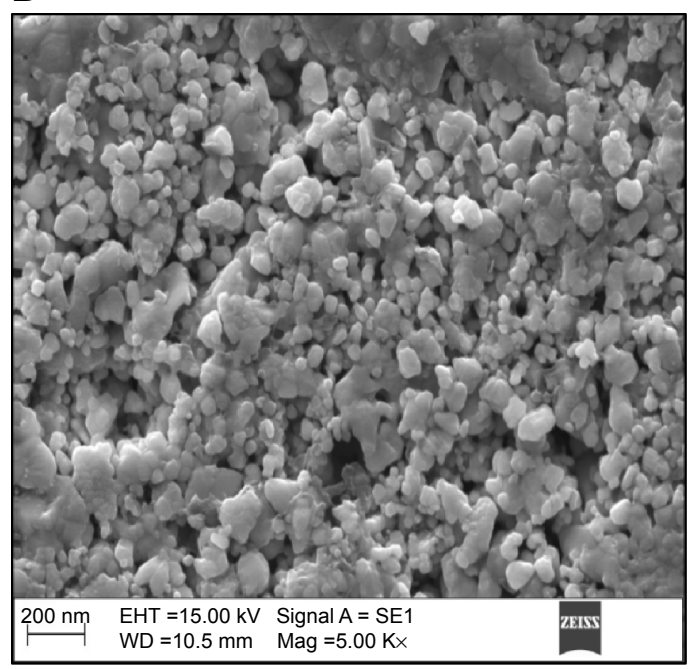

$\mathbf{F}$

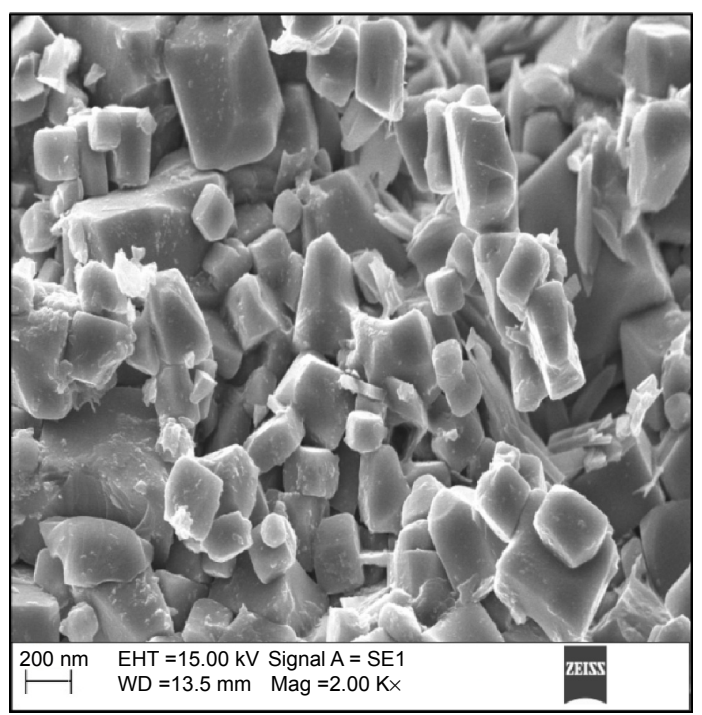

Figure 3 SEM images of pure ATR and cationic charge stabilized nanocrystal formulations.

Notes: (A) pure ATR, (B) pure chitosan, (C) ATR-L (atorvastatin nanocrystals stabilized by Labrasol ${ }^{\circledR}$ alone), (D) ATR-CS , (E) ATR-CS $_{M}$, (F) ATR-CS . (Labrasol ${ }^{\circledR}$; Gattefosse, Saint-Priest Cedex, France).

Abbreviations: ATR, atorvastatin; CS, chitosan; $\mathrm{CS}_{\mathrm{L}}$, low molecular weight chitosan; $\mathrm{CS}_{\mathrm{M}}$, medium molecular weight chitosan; $\mathrm{CS}_{\mathrm{H}}$, high molecular weight chitosan; $\mathrm{SEM}$, scanning electron microscopy; mag, magnification. 


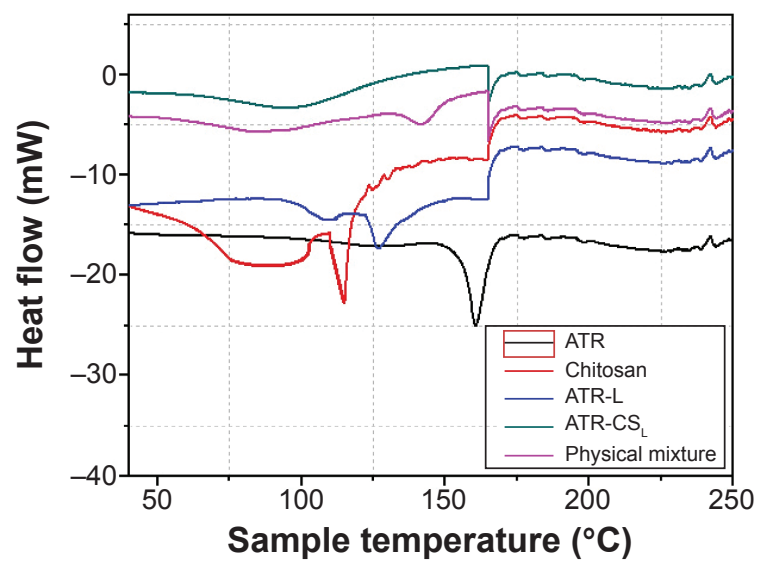

Figure 4 Differential scanning calorimetry thermograms of pure ATR and chitosan stabilized nanocrystal formulations.

Note: Labrasol ${ }^{\circledR}$; Gattefosse, Saint-Priest Cedex, France.

Abbreviations: ATR, atorvastatin; ATR-L, atorvastatin nanocrystals stabilized by Labrasol ${ }^{\circledR}$ alone; CS, chitosan; $\mathrm{CS}_{\mathrm{L}}$, low molecular weight chitosan.

$\left(111.6^{\circ} \mathrm{C}\right)$, ATR-L $\left(132.1^{\circ} \mathrm{C}\right)$, and ATR-CS $\left(137.2^{\circ} \mathrm{C}\right)$, physical mixture $\left(164.4^{\circ} \mathrm{C}\right)$ respectively. The DSC curves of ATR$\mathrm{CS}_{\mathrm{L}}$ nanocrystal formulation as well as physical mixture were different indicating that the initial crystalline forms of drug and excipients were reversed (Figure 4). Minor migration of peaks in the DSC curves of nanocrystal formulation might be due to heat capacity, heating rate, amount of substance that might have influenced the peak position and intensity leading to deviation.

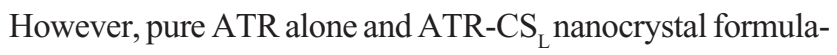
tion show the same characteristic peak indicating no greater interaction between the compositions.

The X-ray powder diffractometry patterns of the pure ATR and that of cationic polymer stabilized nanocrystals were slightly different with few peaks. The pattern exhibited by pure ATR was highly crystalline in nature. As an example, the patterns of pure ATR showed characteristic peaks at $2 \theta=19.8,25.34,44.96,52.07,76.94$, and 93.75 degrees respectively (Figure 5). In contrary to this, patterns of ATR-CS ${ }_{L}$ and ATR-L nanocrystals were also quite similar but exhibited few extra peaks. These peaks were an indication of transformation into slight amorphous state, attributed majorly due to cationic charge size reduction. However, to reach the highest saturation solubility, nanosizing along with amorphous state is reported as ideal which was successfully achieved within nanocrystal formulation. ${ }^{17}$

\section{FT-IR studies}

The IR spectra of pure ATR showed characteristic peaks at $2,923.12 \mathrm{~cm}^{-1}$ (CH-stretching), 1,317.7 $\mathrm{cm}^{-1}$ (C-N-stretching), $3,435.1 \mathrm{~cm}^{-1}$ (N-H-stretching), $1,651.4 \mathrm{~cm}^{-1}(\mathrm{C}=\mathrm{C}$ bending), $1,051.6 \mathrm{~cm}^{-1}(\mathrm{O}-\mathrm{H}-\mathrm{bending})$ respectively. The spectrum of

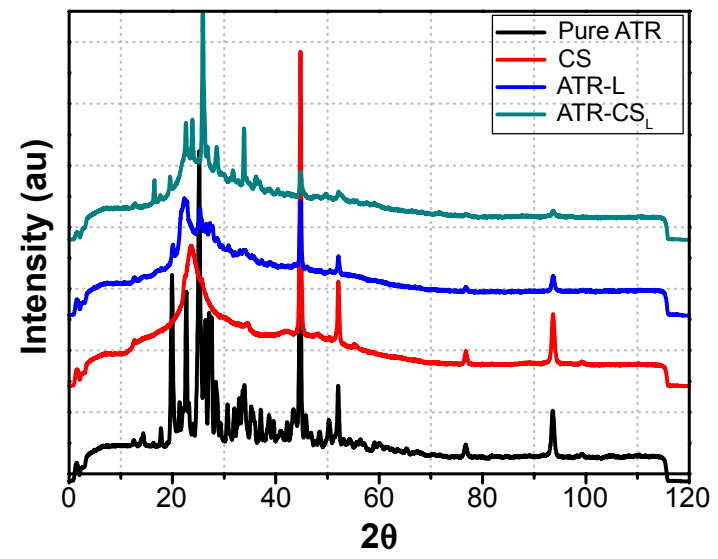

Figure 5 X-RPD of pure ATR and chitosan stabilized nanocrystal formulations. Note: Labrasol ${ }^{\circledR}$; Gattefosse, Saint-Priest Cedex, France.

Abbreviations: au, arbitrary units; ATR, atorvastatin; ATR-L, atorvastatin nanocrystals stabilized by Labrasol ${ }^{\circledR}$ alone; CS, chitosan; $\mathrm{CS}_{\mathrm{L}}$, low molecular weight chitosan; X-RPD, X-ray powder diffractometry.

chitosan showed absorption bands at $1,496.4 \mathrm{~cm}^{-1}$ due to the presence of carboxylates $(\mathrm{C}=\mathrm{O})$. The spectrums of ATR-L and ATR-CS $\mathrm{L}_{\mathrm{L}}$ nanocrystals showed the same characteristic peaks at 2,923.12 $\mathrm{cm}^{-1}$ (CH-stretching), $1,317.7 \mathrm{~cm}^{-1}$ (C-Nstretching), 3,435.1 $\mathrm{cm}^{-1}$ (N-H-stretching), $1,651.4 \mathrm{~cm}^{-1}$ (C=C-bending), 1,051.6 $\mathrm{cm}^{-1}$ (O-H-bending) respectively (Figure 6). No marked difference was observed in the absorption bands (chemical bond) of pure ATR and other ATR nanocrystal formulations. Therefore, the conducted FT-IR studies proved that no possible drug-excipient interactions exist within nanocrystal formulations.

\section{In-vitro dissolution studies}

In order to ascertain, whether the goal to enhance the ATR solubility by nanocrystal technique is achievable, in-vitro dissolution studies were conducted. The dissolution profile of ATR-L nanocrystals was enhanced due to the presence of Labrasol ${ }^{\circledR}$ that has greatly helped in wettability of ATR hydrophobic sites. When compared to other nanocrystal formulations, ATR-L has shown faster dissolution rates of about $60 \%$ released within 5 hours. The effect was majorly due to the absence of polymer stabilizer that could have retarded the ATR release from nanocrystal formulations. Cationic charge size reduction by $\mathrm{CS}_{\mathrm{L}}$ had not only greatly enhanced the dissolution rates of ATR nanocrystals but was also able to retard ATR release for a longer duration of time ie, $40 \%$ in 5 hours and $57 \%$ in 6 hours when compared to marketed product Lipitor ${ }^{\circledR}$ about $79 \%$ in 5 hours and $88 \%$ in 6 hours respectively (Figure 7).

The release of ATR from ATR-CS $\mathrm{L}_{\mathrm{L}}$ nanocrystal formulation in the dissolution media PBS pH 7.4 was much faster when compared to GSF $\mathrm{pH}$ 1.2. The possible reason 


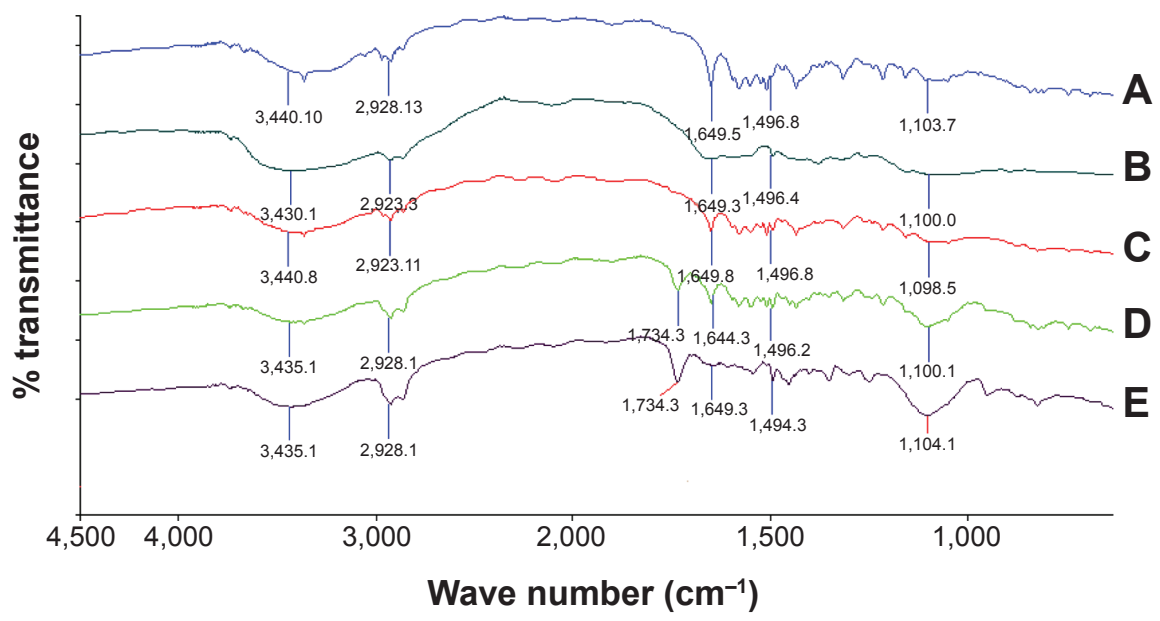

Figure 6 FT-IR spectra of pure ATR and cationic charge stabilized nanocrystal formulations.

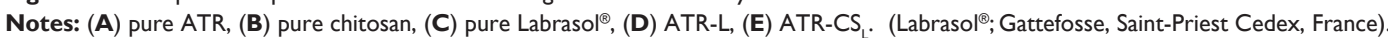

Abbreviations: FT-IR, Fourier transform-infrared; ATR, atorvastatin; ATR-L, atorvastatin nanocrystals stabilized by Labrasol ${ }^{\circledR}$ alone; CS, chitosan; CS, low molecular weight chitosan.

for slower ATR release is majorly due to $\mathrm{CS}_{\mathrm{L}}$ adsorption and swelling behavior of nanocrystals in acidic medium (pH 1.2). The determined release profiles were characterized by indicating sustained release of ATR from $\mathrm{CS}_{\mathrm{L}}$ based nanocrystals. The sustained profile can be potentially beneficial in anti-hyperlipidemia therapy because $\mathrm{CS}_{\mathrm{L}}$ helps in prolonged circulation of nanocrystals within the systemic circulation thereby enhancing the bioavailability of ATR. Moreover, use of chitosan in oral or parenteral drug delivery design is safe with no cytotoxicity or accumulation in major tissue or organs reported due to its biodegradability and nonimmunogenic properties. ${ }^{25}$

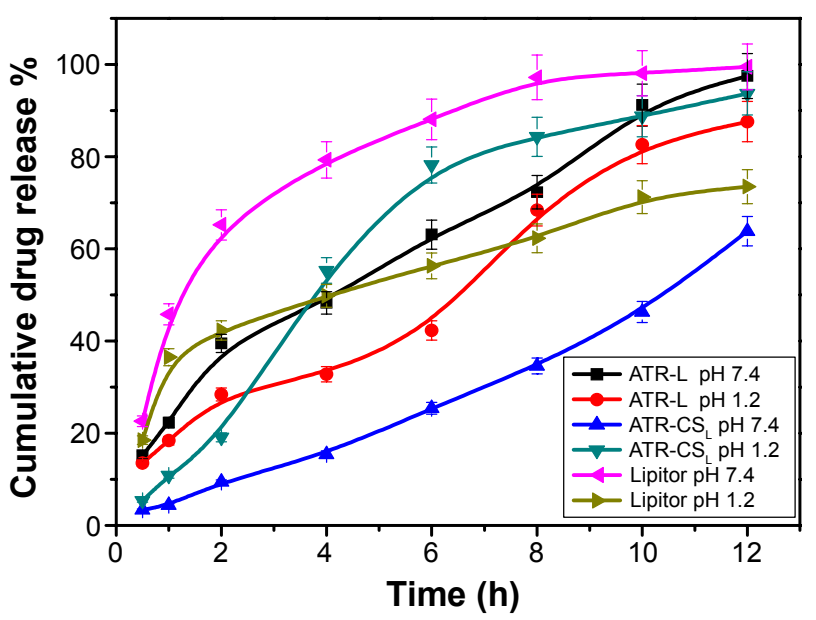

Figure 7 Percentage of cumulative drug release of nanocrystal formulations ATR-L, ATR-CS, Lipitor ${ }^{\circledR}$ in GSF pH I.2 and phosphate buffer pH 7.4.

Notes: Lipitor ${ }^{\circledast}$ (Pfizer, Inc., New York, NY, USA); Labrasol ${ }^{\circledR}$ (Gattefosse, SaintPriest Cedex, France).

Abbreviations: ATR, atorvastatin; ATR-L, atorvastatin nanocrystals stabilized by Labrasol ${ }^{\circledast}$ alone; CS, chitosan; $\mathrm{CS}_{\mathrm{L}}$, low molecular weight chitosan; GSF, gastric stimulated fluid; h, hour(s).

\section{In-vivo anti-hyperlipidemic efficacy studies}

The measure of hyperlipidemia by closely monitoring the serum lipid levels is not only an invaluable quality tool to calculate the major health risk factors but also helps in prevention of cardiovascular diseases such as atherosclerosis, myocardial infarction, and stroke. ${ }^{7}$ Poloxamer 407 is reported as non-ionic synthetic surfactant generally used and administered intraperitoneally to induce hyperlipidemia within 24 hours. ${ }^{33}$ According to literature; $0.5 \mathrm{~g} / \mathrm{kg}$ dose was considered for inducing hyperlipidemia in animals. The resultant increase in lipoprotein concentration was many folds higher due to difficulty in screening pharmacodynamics of ATR nanocrystal formulation. After certain trials, $0.25 \mathrm{~g} / \mathrm{kg}$ was considered fixed dose to induce hyperlipidemia in animals after 24 hours administration. Results indicated that marketed product Lipitor ${ }^{\circledR}$ lowered cholesterol (67.12\% inhibition), triglyceride (62.45\% inhibition), HDL (47.53\% inhibition), and LDL (67.23\% inhibition) in 72 hours respectively. Nanocrystal formulation ATR-CS at $\mathrm{pH} 5$ resulted in greater reduction of cholesterol $(94.91 \%$ inhibition), triglyceride (96.12\% inhibition), HDL (92.3\% inhibition), LDL (99.21\% inhibition) when compared to groups treated with ATR-L and ATR-CS $\mathrm{L}_{\mathrm{L}}$ at $\mathrm{pH} 6$ formulations respectively (Figure 8). The poor efficacy of ATR-L treated group after 72 hours was majorly related to larger particle size and faster elimination of nanocrystals due lack of polymer stabilizer.

$\mathrm{pH}$ of the solution plays a vital role in protonation degree of cationic charge polymer. The extent of electrostatic stabilization mechanism of the cationic polymer is proportional 
A

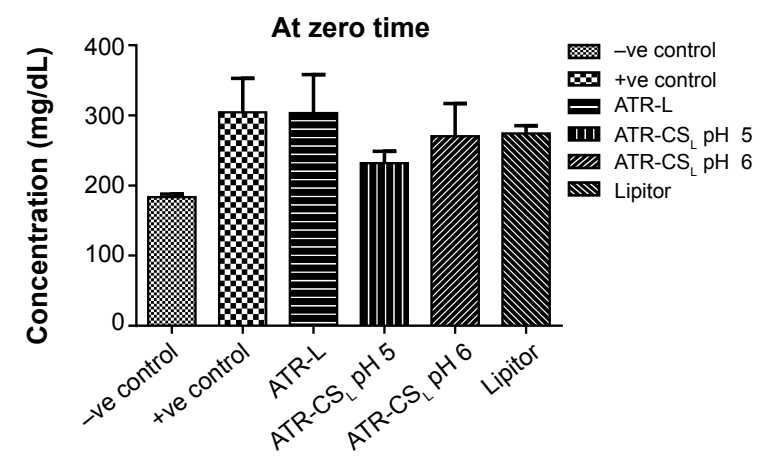

Groups

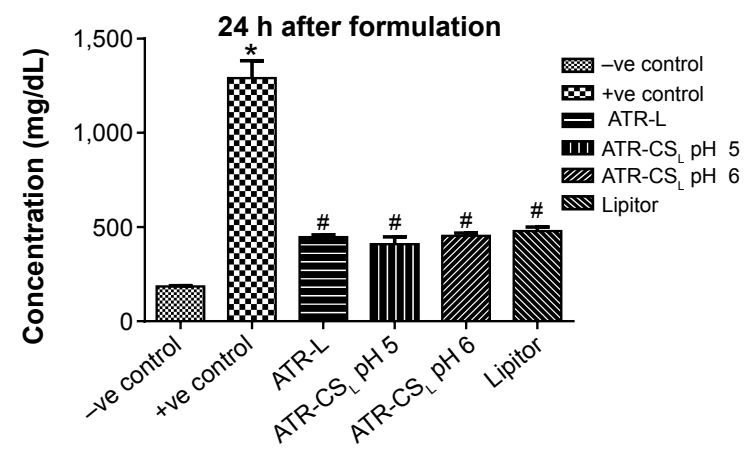

Groups

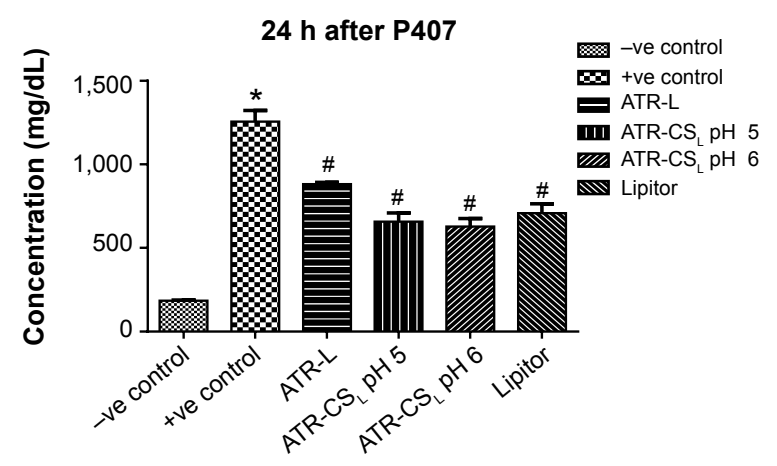

Groups

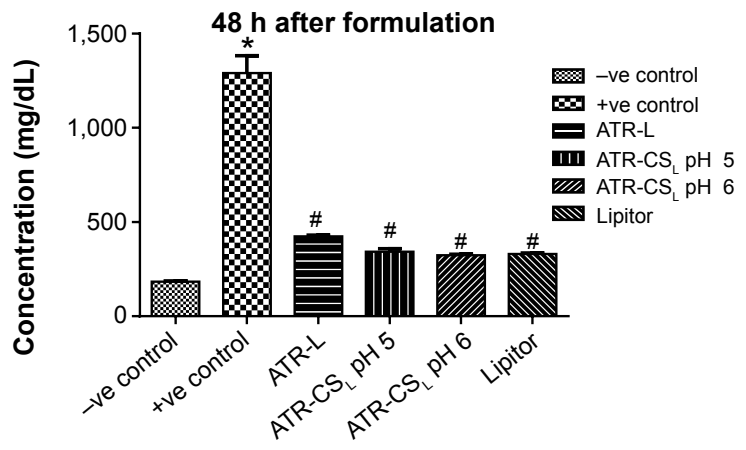

Groups

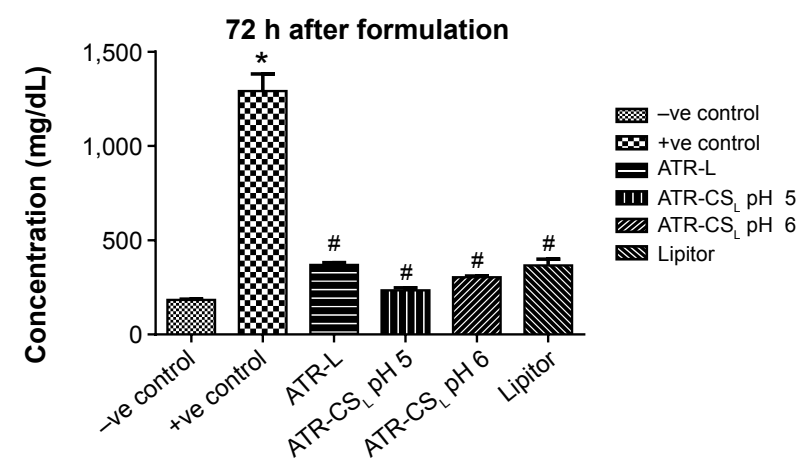

Groups

B

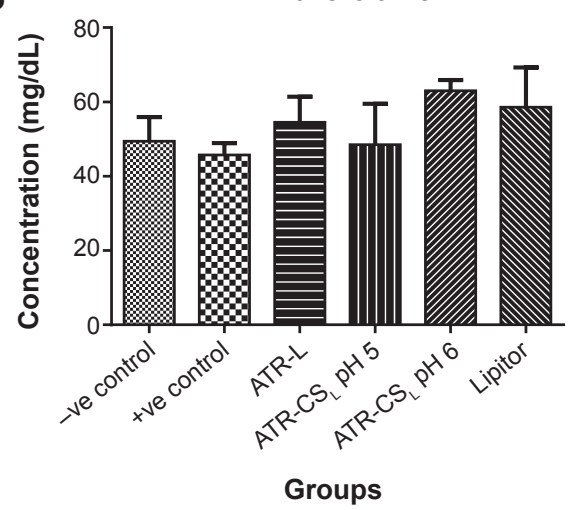

-ve control - ATR-L

III ATR-CS $\mathrm{pH} 5$ III ATR-CS $\mathrm{LH} 6$ LW Lipitor

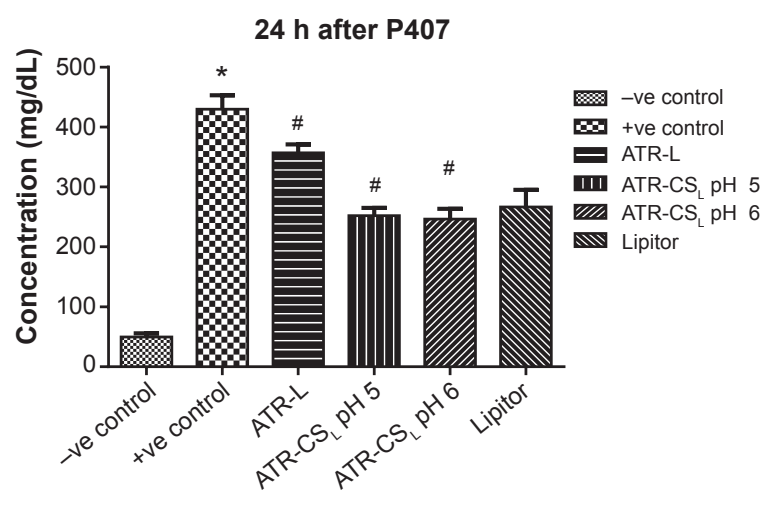

Groups

Figure 8 (Continued) 

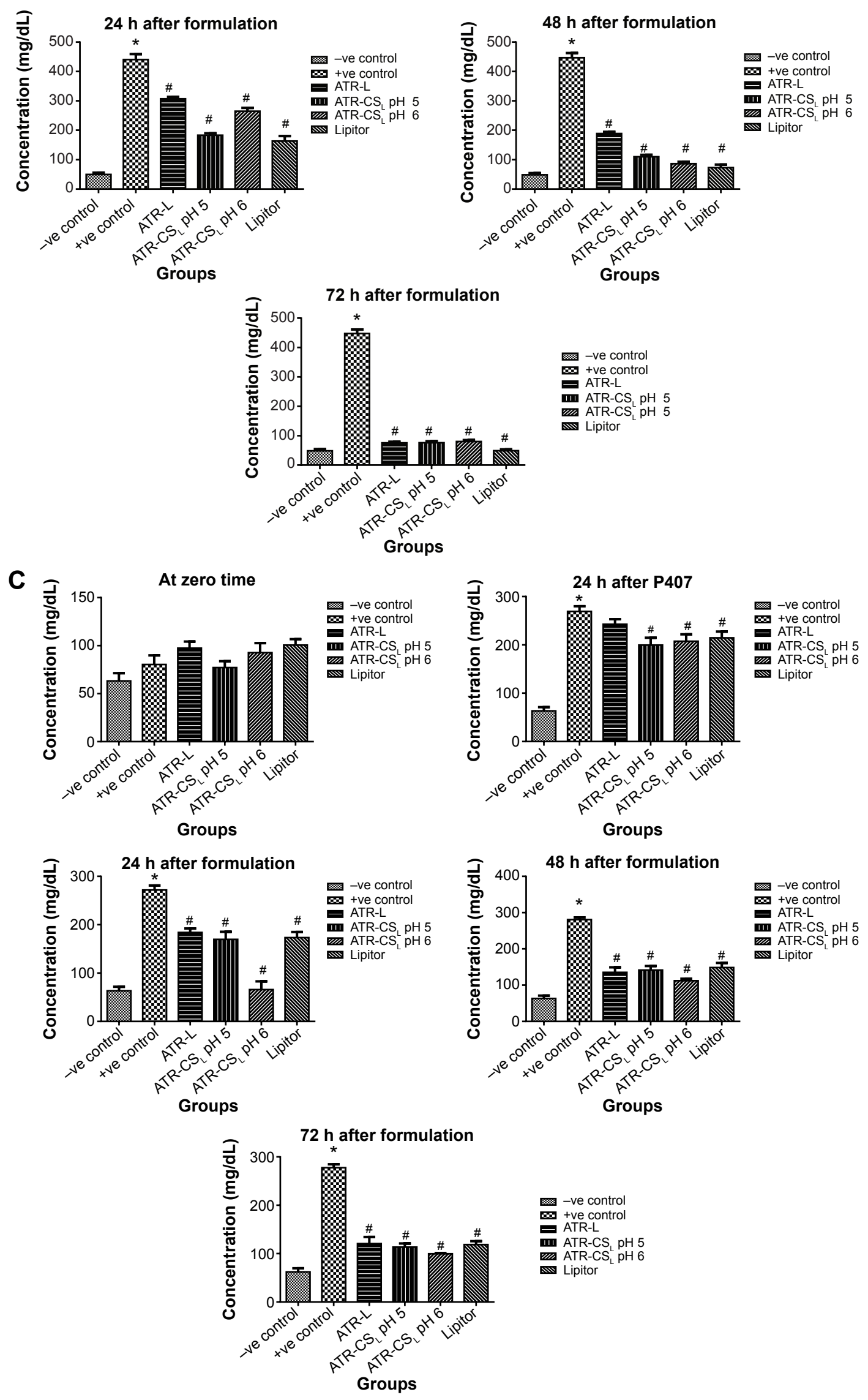

Figure 8 (Continued) 

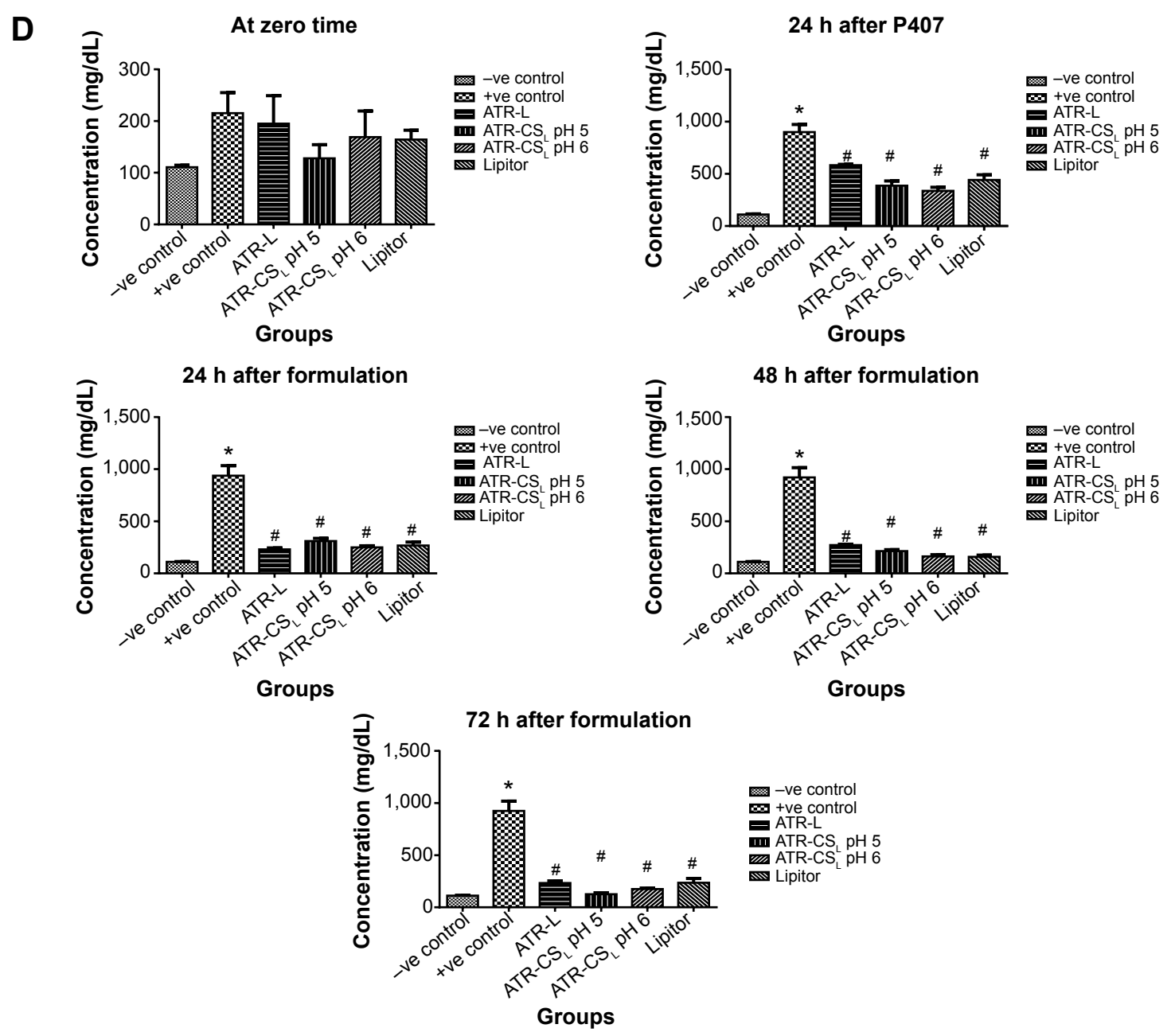

Figure 8 Anti-hyperlipidemic activity (\% inhibition) of cationic polymer stabilized nanocrystal formulations in comparison to Lipitor ${ }^{\circledR}$.

Notes: (A) Total cholesterol, (B) total triglycerides, (C) total HDL, (D) total LDL. *Is significantly different from -ve control at $P<0.05$ while $\#$ Is significantly different from + ve control at $P<0.05$. Lipitor ${ }^{\circledR}$ (Pfizer, Inc., New York, NY, USA); Labrasol ${ }^{\circledR}$ (Gattefosse, Saint-Priest Cedex, France).

Abbreviations: HDL, high density lipoprotein; LDL, low density lipoprotein; h, hour(s); ATR, atorvastatin; ATR-L, atorvastatin nanocrystals stabilized by Labrasol ${ }^{\circledR}$ alone; $\mathrm{CS}$, chitosan; $\mathrm{CS}_{\mathrm{L}}$, low molecular weight chitosan.

to the cationic charge density which influences the extent of particle size reduction. Favorable electrostatic stabilization enhances both in-vitro dissolution and in-vivo efficacy. ${ }^{23}$ The anti-hyperlipidemic activity of ATR-CS $\mathrm{L}_{\mathrm{L}}$ nanocrystal formulation was found to be $\mathrm{pH}$ dependent. The pharmacodynamic activity of nanocrystal formulation at $\mathrm{pH} 5$ was 2.5 -fold higher when compared to $\mathrm{pH} 6$ and marketed product Lipitor $^{\circledR}$. The enhanced in-vivo efficacy at $\mathrm{pH} 5$ was majorly because of higher cationic charge nanosizing and adsorption causing prolonged circulation of nanocrystal in the blood stream, thereby increasing the plasma drug concentration (higher bioavailability) of ATR.

The results of statistical analysis of collected data using one-way ANOVA showed significant difference between Lipitor $^{\circledR}$ and optimized nanocrystal formulations ATR-L and ATR-CS ${ }_{\mathrm{L}}$ at $\mathrm{pH} 5$ and 6 respectively $(P<0.05)$. The experimental outcomes prove nanocrystal technique to be a promising strategy to formulate an oral sustained release dosage form of ATR with enhanced bioavailability and antihyperlipidemic efficacy.

\section{Short-term stability studies}

It was evident that size was greatly changed for ATR-L nanocrystals at 4 and $40^{\circ} \mathrm{C}$ due to occurrence of aggregation. The physical instability of ATR-L nanocrystals indicating change in size and zeta potential is due to lack of stabilizer that could not prevent aggregation by electrostatic repulsions

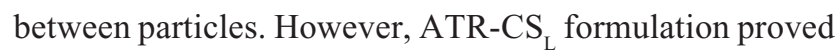
stable at 4 and $25^{\circ} \mathrm{C}$ indicating no possible change of size and zeta potential due to sufficient electrostatic and steric stabilization provided by cationic charge of chitosan over 90 days. At elevated temperature like $40^{\circ} \mathrm{C}$, the nanocrystal 
Table 2 Change in particle size and zeta potential of ATR-L and ATR-CS nanocrystal formulations after 90 days during stability studies $(n=3)$

\begin{tabular}{|c|c|c|c|c|}
\hline Temperature & & Nanocrystal formulation & Particle size (nm) & Zeta potential $(\mathrm{mV})$ \\
\hline \multirow[t]{4}{*}{$4^{\circ} \mathrm{C}$} & 0 day & ATR-L & $549.6 \pm 11.5$ & $-14.26 \pm 1.5$ \\
\hline & & ATR-CS & $345.9 \pm 21.2$ & $21.57 \pm 2.1$ \\
\hline & 90 days & ATR-L & $556.9 \pm 11.2 * *$ & $-16.15 \pm 1.2 * *$ \\
\hline & & ATR-CS & $380.2 \pm 9.5 * *$ & $24.6 \pm 2 . I^{* *}$ \\
\hline \multirow[t]{4}{*}{$25^{\circ} \mathrm{C}$} & 0 day & ATR-L & $549.6 \pm 11.5$ & $-14.26 \pm 1.5$ \\
\hline & & ATR-CS & $345.9 \pm 21.2$ & $21.57 \pm 2.1$ \\
\hline & 90 days & ATR-L & $546.2 \pm 6.1 * *$ & $-21.6 \pm 1.4^{* *}$ \\
\hline & & ATR-CS & $356.5 \pm 5.2 * *$ & $23.6 \pm 2.2^{* *}$ \\
\hline \multirow[t]{4}{*}{$40^{\circ} \mathrm{C}$} & 0 day & ATR-L & $549.6 \pm 11.5$ & $-14.26 \pm 1.5$ \\
\hline & & ATR-CS & $345.9 \pm 21.2$ & $21.57 \pm 2.1$ \\
\hline & 90 days & ATR-L & $602.3 \pm 8.2 * *$ & $-18.9 \pm 2.1 * *$ \\
\hline & & ATR-CS & $410.2 \pm 8.6 * *$ & $28.14 \pm 1.8 * *$ \\
\hline
\end{tabular}

Notes: **There was significant difference between day 0 and 90 days of storage $(P>0.05)$. Labrasol ${ }^{\circledR}$; Gattefosse, Saint-Priest Cedex, France.

Abbreviations: ATR, atorvastatin; CS, chitosan; $C S_{L}$, low molecular weight chitosan; ATR-L, atorvastatin nanocrystals stabilized by Labrasol ${ }^{\circledR}$ alone.

system becomes more thermodynamically unfavorable and unstable resulting in aggregation of particles within ATR-L and ATR-CS ${ }_{\mathrm{L}}$ formulations. ${ }^{31}$ However, a more detailed assessment of stability is required for determining accurate shelf-life of ATR-CS Lanocrystal formulations (Table 2).

\section{Conclusion}

Novel oral chitosan based ATR nanocrystals formulation was successfully developed using a combination of antisolvent and probe sonication method. The method used proved efficient in high drug loading, better size reduction, and cost-effectiveness. Different cationic charges of chitosan were successfully investigated over nanocrystal stabilization and size reduction. Low cationic charged chitosan proved to be effective in size reduction, enhancement of solubility and stability of nanocrystal formulations. The prepared nanocrystals were indicated as slightly amorphous with no possible drug excipient interaction. Nanocrystals formulated with low cationic density proved better stabilization in elevated temperatures when compared to nanocrystals stabilized only by Labrasol ${ }^{\circledR}$. In-vivo anti-hyperlipidemic activity was found to be $\mathrm{pH}$ dependent and significantly (2.5-fold) higher at $\mathrm{pH} 5$ when compared to $\mathrm{pH} 6$ and marketed product Lipitor $^{\circledR}$. $\mathrm{CS}_{\mathrm{L}}$ stabilized nanocrystals can be a promising strategy to formulate oral sustained release dosage forms in order to improve the bioavailability of major Biopharmaceutical Classification System II/IV drugs.

\section{Acknowledgments}

This article is funded by the Deanship of Scientific Research (DSR), King Abdulaziz University, Jeddah. The authors, therefore, acknowledge with thanks DSR for technical and financial support. The authors are also grateful to Mr Hany El-Bassossy, PhD, Department of Pharmacology, Faculty of Pharmacy, King Abdulaziz University for providing invaluable insights in the in-vivo studies.

\section{Disclosure}

The authors have no conflicts of interest to disclose.

\section{References}

1. Kidane A, Bhatt PP. Recent advances in small molecule drug delivery. Curr Opin Chem Biol. 2005;9(4):347-351.

2. Wang B, Siahaan TJ, Soltero RA. Drug delivery: principles and applications. New Jersey: John Wiley and Sons; 2005.

3. Williams HD, Trevaskis NL, Charman SA, et al. Strategies to Address Low Drug Solubility in Discovery and Development. Pharmacol Rev. 2013;65(1):1315-1499.

4. Liversidge GG, Conzentino P. Drug particle size reduction for decreasing gastric irritancy and enhancing absorption of naproxen in rats. Int $J$ Pharm. 1995;125(2):309-313.

5. Kasim NA, Whitehouse M, Ramachandran C, et al. Molecular Properties of WHO Essential Drugs and Provisional Biopharmaceutical Classification. Mol Pharm. 2004;1(1):85-96.

6. Cilla DD Jr, Whitfield LR, Gibson DM, Sedman AJ, Posvar EL. Multipledose pharmacokinetics, pharmacodynamics, and safety of atorvastatin, an inhibitor of HMG-CoA reductase, in healthy subjects. Clin Pharmacol Ther. 1996;60(6):687-695.

7. Law MR, Wald NJ, Rudnicka AR. Quantifying effect of statins on low density lipoprotein cholesterol, ischaemic heart disease, and stroke: systematic review and meta-analysis. BMJ. 2003;326(7404): 1423.

8. Kim JS, Kim MS, Park HJ, Jin SJ, Lee S, Hwang SJ. Physicochemical properties and oral bioavailability of amorphous atorvastatin hemi-calcium using spray-drying and SAS process. Int J Pharm. 2008;359(1-2):211-219.

9. Lau HH, Okochi H, Huang Y, Benet LZ. Pharmacokinetics of atorvastatin and its hydroxymetabolites in rats and the effects of concomitant rifampicin single doses: relevance of first-pass effect from hepatic uptake transporters, and intestinal and hepatic metabolism. Drug Metab Dispos. 2006;34(7):1175-1181. 
10. Lennernas H. Human jejunal effective permeability and its correlation with preclinical drug absorption models. J Pharm Pharmacol. 1997;49(7):627-638.

11. Lennernas H. Clinical pharmacokinetics of atorvastatin. Clin Pharmacokinet. 2003;42(13):1141-1160.

12. Kadu PJ, Kushare SS, Thacker DD, Gattani SG. Enhancement of oral bioavailability of atorvastatin calcium by self-emulsifying drug delivery systems (SEDDS). Pharm Dev Technol. 2011;16(1):65-74.

13. Shen $H$, Zhong M. Preparation and evaluation of self-micro emulsifying drug delivery systems (SMEDDS) containing atorvastatin. JPharm and Pharmcol. 2006;58(9):1183-1191.

14. Miryala V, Kurakula M. Self-nano emulsifying drug delivery systems (SNEDDS) for oral delivery of atorvastatin -formulation and bioavailability studies. J Drug Deliv Therap. 2013;3:131-142.

15. Kim M, Jin S, Kim J, et al. Preparation, characterization and in vivo evaluation of amorphous atorvastatin calcium nanoparticles using supercritical antisolvent (SAS) process. Eur J Pharm Biopharm. 2008;69(2):454-465.

16. Zhang HX, Wang JX, Zhang ZB, Le Y, Shen ZG, Chen JF. Micronization of atorvastatin calcium by antisolvent precipitation process. Int $J$ Pharm. 2009;374(1-2):106-113.

17. Junghanns JU, Muller RH. Nanocrystal technology drug delivery and clinical applications. Int J Nanomedicine. 2008;3(3):295-310.

18. Moschwitzer JP. Drug nanocrystals in the commercial pharmaceutical development process. Int J Pharm. 2013;453(1):142-156.

19. Keck CM, Muller RH. Drug nanocrystals of poorly soluble drugs produced by high pressure homogenisation. Eur J Pharm Biopharm. 2006;62(1):3-16.

20. Crisp MT, Tucker CJ, Rogers TL, William RO 3rd, Johnston KP. Turbidimetric measurement and prediction of dissolution rate of poor soluble drug nanocrystals. J Control Release. 2007;117(3):351-359.

21. Jinno J, Kamada N, Miyaki M, et al. Effect of particle size reduction on dissolution and oral absorption of poor soluble drugs. $J$ Control Release. 2006;111(1-2):56-64.

22. Delongeas JL, Vermeil de Conchard G, Beamonte A, et al. Assessment Labrasol/Labrafil/Transcutol (4/4/2, v/v/v) as a non-clinical vehicle for poorly water-soluble compounds after 4-week oral toxicity study in Wistar rats. Regul Toxicol Pharm. 2010;57(2-3):284-290.

23. Sun W, Tian W, Zhang Y, He J, Mao S, Fang L. Effect of novel stabilizers cationic polymers on the particle size and physical stability of poorly soluble drug nanocrystals. Nanomedicine. 2012;8(4):460-467.

24. Muzzarelli RA. Human enzymatic activities related to therapeutic administration of chitin derivatives. Cell Mol Life Sci. 1997;53(2): 131-140.
25. Hirano S, Seino H, Akiyama Y, Nonaka I. Chitosan: a biocompatible material for oral and intravenous administration, in Oral and Intravenous Administrations. Progress in Biomedical Polymers. 1990;283-289.

26. Mao S, Sun W, Kissel T. Chitosan-based formulations for delivery of DNA and siRNA. Adv Drug Deliv Rev. 2010;62(1):12-27.

27. Mao S, Shuai X, Unger F, Simon M, Bi D, Kissel T. The depolymerisation of chitosan: effects on physiochemical and biological properties. Int J Pharm. 2004;281(1-2):45-54.

28. Lee E, Kim H, Lee IH, Jon S. In vivo antitumor effects of chitosanconjugated docetaxel after oral administration. J Control Release. 2009;140(2):79-85.

29. Lee E, Lee J, Lee IH, et al. Conjugated chitosan as a novel platform for oral delivery of paclitaxel. J Med Chem. 2008;51(20):6442-6449.

30. Dos Santos S, Medronho B, Santos TD, Antunes FE. Amphiphilic Molecules in Drug Delivery Systems. Advan Pred Preven Person Med. 2013;435-485.

31. Lu Y, Wang ZH, Li T, Nally HM, Park K, Sturek M. Development and evaluation of transferrin-stabilized paclitaxel nanocrystal formulation. J Control Release. 2014;176:76-85.

32. Fu Q, Sun J, Ai X, et al. Nimodipine nanocrystals for oral bioavailability improvement: Role of mesenteric lymph transport in the oral absorption. Int J Pharm. 2013;448(1):290-297.

33. Chaudhary HR, Brocks DR. The single dose poloxamer 407 model of hyperlipidemia; systemic effects on lipids assessed using pharmacokinetic methods, and its effects on adipokines. J Pharm Pharm Sci. 2013;16(1):65-73.

34. International Conference on Harmonization [homepage on the Internet]. ICH Harmonized Tripartite guideline. Validation of Analytical Procedures: Text and Methodology Q2 (R1). Current Step 4 version. Parent Guideline dated 27 October 1994. (Complementary Guideline on Methodology dated 6 November 1996; incorporated in November 2005). Available from: http://www.ich.org/fileadmin/Public_Web_Site/ ICH_Products/Guidelines/Quality/Q2_R1/Step4/Q2_R1_Guideline. pdf. Accessed December 11, 2014

35. Kurakula M, Sobahi TR, El-Helw AM, Abdelaal MY. Development and Validation of a RP-HPLC Method for Assay of Atorvastatin and its Application in Dissolution Studies on Thermosensitive HydrogelBased Nanocrystals. Trop J Pharm Res. 2014;13(10):1681-1687.

36. International Conference on Harmonization [homepage on the Internet]. ICH Harmonized Tripartite guideline. Q1A (R2) Stability Testing of New Drug Substances and Products. Step 4; 2003. Available from: http://www.ich.org/fileadmin/Public_Web_Site/ICH_Products/ Guidelines/Quality/Q1A_R2/Step4/Q1A_R2_Guideline.pdf. Accessed December 11, 2014
International Journal of Nanomedicine

\section{Publish your work in this journal}

The International Journal of Nanomedicine is an international, peerreviewed journal focusing on the application of nanotechnology in diagnostics, therapeutics, and drug delivery systems throughout the biomedical field. This journal is indexed on PubMed Central, MedLine, CAS, SciSearch ${ }^{\circledR}$, Current Contents ${ }^{\circledR} /$ Clinical Medicine,

\section{Dovepress}

Journal Citation Reports/Science Edition, EMBase, Scopus and the Elsevier Bibliographic databases. The manuscript management system is completely online and includes a very quick and fair peer-review system, which is all easy to use. Visit http://www.dovepress.com/ testimonials.php to read real quotes from published authors. 